\title{
Inequalities in energy-balance related behaviours and family environmental determinants in European children: changes and sustainability within the EPHE evaluation study
}

Krystallia Mantziki ${ }^{*}$, Carry M. Renders ${ }^{1}$, Achilleas Vassilopoulos², Gabriella Radulian ${ }^{3}$, Jean-Michel Borys ${ }^{4}$, Hugues du Plessis ${ }^{4}$, Maria João Gregório ${ }^{5}$, Pedro Graça, ${ }^{5,6}$, Stefaan de Henauw ${ }^{7}$, Svetoslav Handjiev ${ }^{8}$, Tommy L. S. Visscher ${ }^{1,9,10}$ and Jacob C. Seidell ${ }^{1}$

\begin{abstract}
Background: Increasing social inequalities in health across Europe are widening the gap between low and high socio-economic groups, notably in the prevalence of obesity. Public health interventions may result in differential effects across population groups. Therefore, the EPHE (EPODE for the Promotion of Health Equity) project analysed the added value of community-based programmes, based on the EPODE (Ensemble Prévenons I'Obésité Des Enfants-Together Let's Prevent Obesity) model, to reduce socio-economic inequalities in energy balance-related behaviours of children and their family-environmental related determinants in seven European communities. This study presents the changes between baseline and follow-up after the one-year interventions and their sustainability one year after.

Methods: This is a prospective study with a one school-year intervention, followed by one year of follow-up. In all, 1266 children (age 6-8 years) and their families from different socio-economic backgrounds were recruited at baseline. For 1062 children, information was available after one year $\left(T_{1}\right)$ and for 921 children after two years $\left(T_{2}\right)$. A self-reported questionnaire was completed by the parents to examine the children's energy balance-related behaviours and family- environmental determinants. Socio-economic status was defined by the educational level of the mother. The Wilcoxon signed-rank test for paired data was used to test the differences between baseline and intermediate, and between intermediate and final, measurements for each of the socio-economic status groups.

Results: Post-intervention effects in energy-balance related behaviours showed the following improvements among the low socio-economic status groups: increased fruit consumption (Netherlands), decreased fruit juices amount consumed (Romania) and decreased TV time on weekdays (Belgium). Whereas in only the latter case the behavioural change was accompanied with an improvement in a family-environmental determinant (monitoring the time the child watches TV), other improvements in parental rules and practices related to soft drinks/fruit juices and TV exposure were observed. A few of those effects were sustainable, notably in the case of Belgium.

(Continued on next page)
\end{abstract}

\footnotetext{
* Correspondence: k.mantziki@vu.nl

${ }^{1}$ Department of Health Sciences, VU University Amsterdam, De Boelelaan

1085, 1081HV Amsterdam, The Netherlands

Full list of author information is available at the end of the article
} 
(Continued from previous page)

Conclusions: Inequalities in obesity-related behaviours could be potentially reduced when implementing community-based interventions, tailored to inequality gaps and using the EPODE methodology. Within-group changes varied widely, whereas monitoring of interventions and process evaluation are crucial to understand the observed results.

Keywords: Health inequalities, Lifestyle behaviours, Parenting practices, EPODE, Evaluation

\section{Background}

Tackling inequalities in overweight, obesity and related determinants is high on the political and public health agenda in many European countries [1-6]. Socio-economic inequalities in obesity cases may develop in early childhood and last throughout the later stages of life $[7,8]$, while childhood is a critical period for shaping future behaviours. Therefore targeting children and their parents to reduce these socioeconomic inequalities is of major importance. However, most studies assess the effects of interventions in reducing overall obesity levels instead of reducing obesity-related inequalities [9]. Consequently, studies reporting the types of interventions that are effective in reducing such inequalities -particularly in children- are scarce $[3,5,6,9,10]$.

Public health interventions may particularly reach people with a relatively high income and education and they thereby may increase inequalities, despite being effective on the general population $[9,11-15]$. This is defined as the 'intervention-generated inequality', which evolves from the 'inverse care law' [16], meaning that the groups/populations mostly in need of health care are the least likely to benefit from it $[12,15,17]$. It is possible that intervention-generated inequality may happen at several (if not at any) points of the planning and the implementation of an intervention (i.e., intervention efficacy, service provision or access, uptake, compliance) $[6,12,14,17]$. Victora et al. demonstrated that the widening of the inequality gap by the newly introduced interventions occurs due to preferential uptake of the intervention by the most advantaged groups, before the narrowing of the inequality can take place $[6,18]$. In the literature, several attempts have been made to explain this phenomenon by relating it to low compliance [14], the sources of being disadvantaged $[6,18]$ and low participation rates [13]. Nevertheless, further research is needed to determine the specific components of interventions that result in intervention-generated inequalities [6, 17].

Several authors have attempted to specify which interventions may decrease or widen inequalities with regards to obesity. Existing evidence from universal interventions aiming at childhood obesity prevention is mixed. Bambra et al. systematically assessed the effectiveness of interventions to reduce inequalities in childhood obesity and concluded that school-based universal interventions, combining nutrition and physical activity knowledge activities had the potential to have a positive impact on low socioeconomic status children, if the interventions lasted for more than six months [19]. Other studies identified that community and/or school-based interventions were successful in reducing inequalities in obesity outcomes or did not increase them $[12,13,15]$, especially when environmental change components were included [20]. Toybox, a kindergarten-based intervention aiming to increase physical activity- was only effective in the high socioeconomic kindergartens [21], whereas the "Health in Adolescents" study was effective in the middle and high education groups [11].

Another body of evidence suggests that interventions targeting the more/most disadvantaged are likely to reach the low socioeconomic groups and reduce inequalities, as long as they are strategically designed and implemented [17, 22, 23]. According to Laws et al., targeted interventions demonstrated improvement in obesity-related outcomes in low socioeconomic status populations, although most of the reviewed research was of low quality [22]. The most recent reviews suggest that upstream, community-based and multilevel interventions are more likely to reduce inequalities in health, taking into account the involvement of the hard-to-reach target groups, integrating their needs and wishes in the implementation strategies and delivering multiple interventions [12-14, 19, 22].

In response to that evidence and based on the reduction of health inequality in child obesity and overweight through the EPODE (Ensemble Prévenons l'Obésité Des EnfantsTogether let's prevent obesity) methodology [24-26], the EPHE (Epode for the Promotion of Health Equity) project was launched (http://www.ephestory.eu/). The overall aim of the EPHE project was to assess the impact and sustainability of EPODE to diminish inequalities in childhood obesity and overweight (Table 1). Based on scientific evidence [27-30], the EPHE scientific advisory board selected four behaviours related to obesity and overweight, which were addressed by the EPHE interventions: promotion of 1 . Fruit and vegetable intake, 2. Tap water intake, 3. Active lifestyle and 4. Adequate sleep duration. The methods and framework of the EPHE project are summarised in Table 2 and the timeline is illustrated in Fig. 1. 
Table 1 Objectives of the EPHE project

The EPHE project aims to analyse from 2012 to 2015:
- The added value of the implementation of an adopted EPODE
methodology for the reduction of socioeconomic inequalities in health
implemented by 7 European community-based programmes, focusing
on four energy balance-related behaviours (fruit and vegetable
consumption, tap water intake, sedentary behaviour, sleep duration)
and their family-environmental determinants.
- Opportunities to sustain the implementation of EPHE best practices in
other EU regions and member states via EU structural funds, focusing
on the replicability and transferability, at a longer scale, of those to
leverage the experience to develop action plans by member states
and to make use of structural funds for the promotion of health
equity [33].
EPHE worked at the community level in key settings to develop
integrated action locally [33].

The EPHE programmes developed community-based interventions (September 2013-May 2014) addressing the four behaviours and related determinants which were unhealthier in the low socio-economic groups than in the high socio-economic groups [31]. Therefore, the objectives of the current paper are: a) to assess changes in energy-balance related behaviours and family-environmental determinants within both the high and the low education groups by comparing the baseline $\left(T_{0}\right)$ with the intermediate $\left(T_{1}\right)$ measurements, after the termination of the interventions, after one year; b) to assess the sustainability of potential improvements identified after the interventions $\left(\mathrm{T}_{1}\right)$ a year after $\left(\mathrm{T}_{2}\right)$. The article focuses on changes in behaviours and determinants related to the inequality gaps that were identified at the baseline measurement [33].

\section{Methods}

The EPHE evaluation study is based on one school-year of lifestyle interventions aimed at children and their parents, followed by one year of follow-up. The interventions were carried out in seven European countries. This study aims: a) to identify differences in energy balancerelated behaviours and related family-environmental

Table 2 Summary of the EPHE methods and framework

- Seven European community-based programmes, following the EPODE or similar methodology, participated in the EPHE project.

- The programmes recruited (at baseline) families with children aged between 6 to 9 years old from different socio-economic backgrounds, through schools.

- The programmes developed interventions for the whole population, each addressing the relevant inequality gaps identified at baseline [31].

- Intervention target: to improve energy balance-related behaviours and their family-environmental determinants of low socio-economic status families with children 6-9 years old

- Evaluation of the interventions' effects after the intervention period and sustainability assessment a year after [33]. determinants, between high and low status socioeconomic groups, b) to assess the potential decrease of inequality gaps after tailored interventions and c) to assess the sustainability of potential improvements a year after the termination of the interventions. More information about the identified health inequalities within the EPHE study can be found elsewhere [31].

\section{Sample and recruitment}

Seven community-based programmes, which are part of the Epode International Network and implement the EPODE methodology, participate in the EPHE project: VIASANO (Belgium), EPODE (France), PAIDEIATROFI (Greece), Maia Healthy Menu (Portugal), SETS (Romania), JOGG (The Netherlands) HEALTHY KIDS (Bulgaria); the latter programme is part of the Nestlés Healthy Kids programme and implements a similar methodology to EPODE. Every programme participated in EPHE project through communities within an EPODE city. We aimed at recruiting a minimum of 150 families with children aged between 6 to 8 years old in every selected EPODE community with a similar variation regarding age and ethnicity per site. We obtained convenience samples which are not necessarily representative to the country, which was beyond the scope of this study. Each of the programmes conducted the recruitment through schools. The survey obtained a permission waiver from the Medical Ethics Committee of the VU University Medical Centre. In addition, permission to research in schools was acquired from the local community and/or school authorities, where necessary. More information about sampling and recruitment are described elsewhere [32].

\section{EPHE intereventions}

The EPHE programmes developed and implemented general community-based interventions for the selected behaviours towards the whole community, but primarily of children and parents, between September-December 2013. After the dissemination of the baseline results (September 2013), the programmes were instructed to conduct interventions tailored to the inequality gaps identified at baseline [31]. The EPHE Operational Board, comprising the national programme coordinators of each of the participant programmes, was responsible for the continuous training, empowerment and support of the local project managers of the communities, to design and implement the activities in accordance to the EPODE methodology. Thus, the board held frequent meetings and contacts to facilitate competence building and methodology transfer to the local level. Consequently, and as being the core of the EPODE methodology, various community stakeholders were involved, such as municipal representatives, school personnel, 


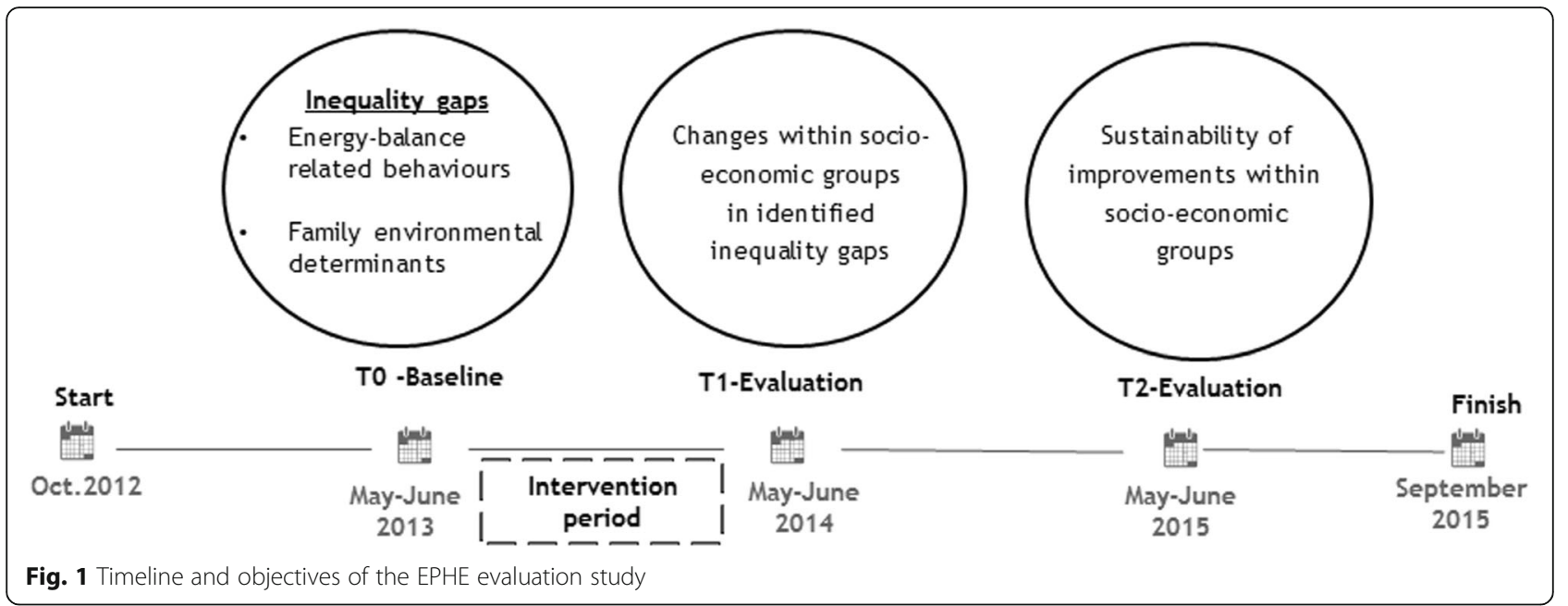

health organisations et cetera. This active involvement of community actors was crucial for implementing activities tailored to the community situation. To avoid stigmatization, all children of the communities (or schools in the case of the JOGG programme, municipality of Zwolle) were invited to participate to the activities, although these were tailored in behaviours and family environmental determinants, which were unhealthier in the low than in the high socio-economic groups. However, due to time constrains the majority of the programmes were able to target only the energybalance related behaviours and not the determinants. Examples of activities held within the EPHE project are games, workshops and educational materials on healthy diet, psychical activity and sleep. More information about the type of implemented activities, stakeholder involvement and implementation methods are included elsewhere [33].

\section{Data collection}

School teachers distributed the questionnaires, including an informed consent form, to the children who consequently delivered them to their parents, after the intervention period between May/June 2014 $\left(\mathrm{T}_{1}\right)$ and a year later, May/June $2015\left(\mathrm{~T}_{2}\right)$. After a specified period of one to two weeks, the completed questionnaires were returned likewise to the teachers. Thereafter, the EPHE project managers collected the questionnaires from the schools and only the ones including a signed informed consent form were taken into consideration. In order to ensure the confidentiality of the data, a process to guarantee anonymity of participant families was applied [33].

\section{EPHE parental questionnaire}

It is well documented that a sustained positive energy balance in children is associated with several lifestyle behaviours, such as, low consumption of fruit and vegetables, high sugar intake, high fat intake, unhealthy snacking, physical inactivity, high screen time and short sleep duration [27-30]. In addition studies have demonstrated associations between the family environment parental practices, rules and behaviours and the children's energy-balance related behaviours [34-36]. The EPHE scientific advisory board selected to address the following behaviours: fruit and vegetable intake, tap water intake, sugary beverages intake (i.e., fruit juices and soft drinks), screen exposure (i.e., television and computer) and adequate sleep duration. Furthermore, associated family-environmental determinants were assessed [34-36].

In order to assess differences in energy-balance related behaviours and their determinants among different socio-economic groups (inequality gaps), a selfadministered parental questionnaire was developed. The EPHE parental questionnaire was developed using items from relevant, validated questionnaires addressed in European populations: ENERGY parent and child questionnaires [34], the Pro-children child questionnaire [35] and its updated version PROGREENS [36], European Health Examination Survey questionnaire [37], European Social Survey questionnaire [38], United States Department of Agriculture questionnaire [39]. Additional items were constructed in the cases where, to our knowledge, no validated items or questionnaires existed.

\section{Assessment of energy-balance related behaviours}

The questionnaire assessed four energy-balance related behaviours of the child: 1 . fruit and vegetable consumption; 2. soft drink/fruit juices and water consumption; 3 . TV or computer screen time and 4. sleep duration, as well as determinants related to the social and physical environment of the child, within the family setting. In order to keep the 
length of the questionnaire within acceptable limits, we had to prioritise the many aspects of behaviour that could be relevant. The EPHE scientific advisory board decided (in consultation with experts) to keep sedentary behaviour as the indicator of physical activity. Other relevant aspects, which were not included, were snacks and meals (such as breakfast, lunch and dinner).

The consumption of fruits and vegetables was assessed by food frequency questions, referring to a usual week and measured on an 8-point Likert scale (1. Never - 8. Every day, more than twice a day) $[32,35,36]$. The consumption of fruit juices, soft drinks and diet soft drinks was measured by means of weekly frequency and amount consumed. The frequency was measured on a 7 point Likert scale (1. Never - 7. Every day, more than once a day) $[32,34]$. The amount was measured by two items for fruit juices and three items for soft and diet soft drinks, assessing how many glasses (or small bottles; $250 \mathrm{ml})$, cans $(330 \mathrm{ml})$ or big bottles $(500 \mathrm{ml})$ the children drink [32, 34]. The amount was calculated by summing up the portions. In order to measure water consumption, two questions were constructed to measure the daily frequency (1. Never - 7. More than six times a day) and number of glasses consumed when drinking water (1. None - 6. five or more glasses). Sedentary behaviour is assessed by means of daily time spent in television (TV) viewing and time of computer (PC) use, for the week and the weekend days separately, measured on a 9-point Likert scale (1. Not at all - 9. 4.0 or more hours a day) [32, 34]. The total screen time was calculated by the sum of weekly (hours per weekday* $5+$ hours per weekend day*2) TV and PC use. Furthermore, two questions informed by the ENERGY parent questionnaire assess the sleeping habits of the child (1. Sleeping routine; 2. Sleep duration per week/ weekend-day) [32, 34].

\section{Assessment of determinants}

The determinants assessed refer to the social and physical family environment of the child. These were mainly assessed by one item and most of them were measured on a 5-point Likert-type scale (0. Never - 4. Always or -2 . Fully disagree - 2. Fully agree), unless otherwise stated below and in the tables of this article; more details are described in Mantziki et al. [32]. The social environmental determinants are: a) for fruit and vegetable consumption, i. Parental demand (0. Never - 4. Yes, always), ii. Parental allowance (0. Never - 4. Yes, always), iii. Active encouragement (-2. Fully disagree - 2. Fully agree) and iv. Facilitating (0. Never - 4. Yes, always) and v. Parental knowledge on recommendations (1. no fruit -8 . 5 pieces per day $[32,35,36]$; b) for fruit juice/soft drink consumption and TV viewing/computer exposure, i. Paying attention/ monitoring (0. Never - 4. Always), ii. Parental allowance
(0. Never - 4. Always), iii. Negotiating (0. Never - 4. Always), iv. Communicating health beliefs (0. never 4. always), v. Avoid negative modelling (0. never - 4 . always), vi. Parental self-efficacy to manage child's intake (0. never - 4. always), vii. Rewarding/comforting practice (0. Never - 4. Always), viii. Conducting energy-balance related behaviour together with the child (1. Never- 8. Every day more than once; for TV viewing/computer time the scale is ' 0 . Never - 4. Always') $[32,34]$. The physical environmental determinants are: a) for the consumption of fruit and vegetables, i. home availability (0. Never - 4. Always) and ii. Situation specific habit (-2. Fully disagree - 2. Fully agree) $[32,35,36]$ b) for fruit juices/soft drinks consumption, i. Home availability (0. Never - 4. Yes, always) and ii. Situation specific habit (1. Yes - 2. No) [32, 34]; and c) for $T V$ viewing \computer exposure, i. Availability (1. Yes - 2. No) ii. Situation specific habit (TV on during mealtime) (1. Every day - 5. Never) [32, 34].

\section{Socioeconomic measures}

The socio-economic status indicators measured were parental employment status, perception of income position, parental educational level, parental sector of employment. The aforementioned variables are described in detail by Mantziki et al. [32]. Knowing that maternal educational level has been classified as a good social factor explaining differences in nutritional outcomes in children [40-42], for the current study, the samples were divided into two groups based on the educational level of the mother (low-high). The educational level was assessed by a 6-point ordinal scale, measuring the years of education accomplished (1. Less than 6 years -6 . More than 17 years; Table 3 ). For each country's sample the median of the educational level was used as the cut-off point to define the educational level of the mother (low-high).

\section{Statistical analysis}

The Wilcoxon signed-rank test for the ordinal and McNemar's test of paired proportions for the binomial variables were used to detect differences in energy-balance related behaviours and determinants a. between $T_{0}$ and $T_{1}$ within the low and within the high education groups, for the variable where an inequality gap was identified at $\mathrm{T}_{0}$; b. between $T_{1}$ and $T_{2}$ within both the low and high education groups, in the variables where an improvement was observed between $\mathrm{T}_{0}-\mathrm{T}_{1}$. The complete follow-up samples for were analysed, which differed in number between $T_{1}$ and $\mathrm{T}_{2}$. Here we present medians and quartile ranges for the ordinal variables and percentages for the binomial variables, in order to illustrate the differences within both the low and high education groups. Knowing that the mean ranks produced by non-parametric tests are not always 
Table 3 Socio-demographic characteristics of the EPHE population per country after the interventions and $\left(T_{1}\right)$ and after one year $\left(T_{2}\right)$

\begin{tabular}{|c|c|c|c|c|c|c|c|c|}
\hline \multirow[t]{2}{*}{ Country } & \multicolumn{2}{|l|}{ Gender } & \multirow{2}{*}{$\begin{array}{l}\text { Age child (years) } \\
\text { Mean (SD) }\end{array}$} & \multicolumn{2}{|c|}{ Age of mother ${ }^{b}$} & \multicolumn{2}{|c|}{ Educational level mother } & \multirow[t]{2}{*}{ Total $\mathrm{n}^{\mathrm{a}}$} \\
\hline & Boys (\%) & Girls (\%) & & $<30(\%)$ & $>30(\%)$ & High (\%) & Low (\%) & \\
\hline \multicolumn{9}{|l|}{$\mathrm{T}_{1}$} \\
\hline Belgium & $82(51,6)$ & $77(48,4)$ & $7,62(, 52)$ & $18(14,0)$ & $113(86,0)$ & $73(45,6)$ & $87(54,4)$ & 160 \\
\hline Bulgaria & $71(46,1)$ & $83(53,9)$ & $8,68(, 50)$ & $5(4,0)$ & $122(96,0)$ & $116(75,3)$ & $38(24,7)$ & 154 \\
\hline France & $37(35,2)$ & $68(64,8)$ & $6,87(, 73)$ & $22(22,6)$ & $55(77,4)$ & $41(39,0)$ & $64(61,0)$ & 105 \\
\hline Greece & $67(51,1)$ & $64(48,9)$ & $8,32(, 63)$ & $2(1,8)$ & $108(98,2)$ & $70(53,4)$ & $61(46,6)$ & 131 \\
\hline Portugal & $90(48,9)$ & $94(51,1)$ & $7,87(, 76)$ & $12(7,3)$ & $152(92,7)$ & $86(46,7)$ & $98(53,5)$ & 184 \\
\hline Romania & $89(55,6)$ & $71(44,4)$ & $8,31(, 49)$ & $21(15,9)$ & $111(84,1)$ & $86(53,1)$ & $76(46,9)$ & 162 \\
\hline The Netherlands & $28(43,1)$ & $37(56,9)$ & $8,51(, 65)$ & $1(1,9)$ & $53(98,9)$ & $46(70,8)$ & $19(29,2)$ & 65 \\
\hline Total & $468(48,0)$ & $498(52,0)$ & $8,02(, 82)$ & $81(9,9)$ & $732(90,1)$ & $516(53,8)$ & $444(46,2)$ & 961 \\
\hline \multicolumn{9}{|l|}{$\mathrm{T}_{2}$} \\
\hline Belgium & $69(50,0)$ & $69(50,0)$ & $8,5(, 50)$ & $12(10,0)$ & $108(90,0)$ & $74(53,2)$ & $65(48,6)$ & 139 \\
\hline Bulgaria & $60(45,5)$ & $72(54,5)$ & $8,98(, 12)$ & $9(7,5)$ & $112(92,5)$ & $97(72,4)$ & $37(27,6)$ & 134 \\
\hline France & $29(35,8)$ & $52(64,2)$ & $7,87(, 68)$ & $12(15,6)$ & $65(84,4)$ & $32(39,5)$ & $49(60,5)$ & 81 \\
\hline Greece & $53(50,0)$ & $53(50,0)$ & $8,88(, 33)$ & $0(0,0)$ & $95(100)$ & $50(46,7)$ & $57(53,3)$ & 107 \\
\hline Portugal & $73(47,7)$ & $80(52,3)$ & $8,64(, 48)$ & $9(6,3)$ & $134(93,7)$ & $82(53,6)$ & $71(46,4)$ & 153 \\
\hline Romania & $78(54,2)$ & $65(45,1)$ & $8,94(, 23)$ & $6(4,4)$ & $129(95,6)$ & $77(53,5)$ & $67(46,5)$ & 144 \\
\hline The Netherlands & $16(44,4)$ & $20(55,6)$ & $8,89(, 32)$ & $0(0,0)$ & $36(100)$ & $27(75,0)$ & $9(25,0)$ & 36 \\
\hline Total & $378(47,9)$ & $411(52,1)$ & $8,70(, 52)$ & 6,9 & 93,1 & 53,7 & 46,3 & 794 \\
\hline
\end{tabular}

${ }^{a}$ Total number of subjects that were followed-up and provided information for the educational level of the mother'; the number reflects the subjects included in the analysis

${ }^{\mathrm{b}}$ The analysis includes the age of the mother only when the mother was the respondent; the age of the second parent was not assessed; Response categories: $1=$ Below 20, $2=21-24,3=25-30,4=31-35,5=36-40,7=$ Above 40 . Number of subjects included in "age of mother" per country were a. at $T_{1}:$ Belgium = 129, Bulgaria $=127$, France $=97$, Greece $=110$, Portugal $=164$, Romania $=132$, The Netherlands $=54$, Total $=813 ; b$. at $T_{2}:$ Belgium $=116$, Bulgaria $=121$, France $=73$, Greece $=86$, Portugal $=136$, Romania $=120$, The Netherlands $=54$, Total $=684$

sufficiently informative and that differences in spread may be equally important as differences in medians [43], further assessment of frequencies and distributions was explored. The results of the additional assessments are not presented in this article due the large amount of information.

All analyses were conducted using the SPSS software v. 21.0 package (IBM Corp., Armonk, NY, USA).

Adjustment for multiple testing was conducted for the intermediate measurements $\left(T_{1}\right)$, using the Benjamini and Hochberg method [44], using the Stata software v. 13 package (StataCorp. 2013. Stata Statistical Software: Release 13. College Station, TX: StataCorp LP).

\section{Results}

A total of 1061 children and their families were involved in the survey at the end of the interventions $\left(\mathrm{T}_{1}\right)$ and 921 in the final survey one year after the end of the interventions $\left(\mathrm{T}_{2}\right)$. Due to missing data in the variable 'educational level of mother', finally 961 and 794 subjects were included in the analysis in $T_{1}$ and $T_{2}$ respectively. On average, the percentage of those cases lost to followup at $\mathrm{T}_{1}$ was $30 \%$, whereas it increased to $34 \%$ at $\mathrm{T}_{2}$. The dropout of the low education group was higher in nearly all countries in both follow-up periods, as illustrated in Figs. 2 and 3.

Tables 4, 5, 6, 7 present only the changes in behaviours that differed between children from low and high socioeconomic background (inequality gaps) at baseline [31] Similarly the respective changes in determinants are

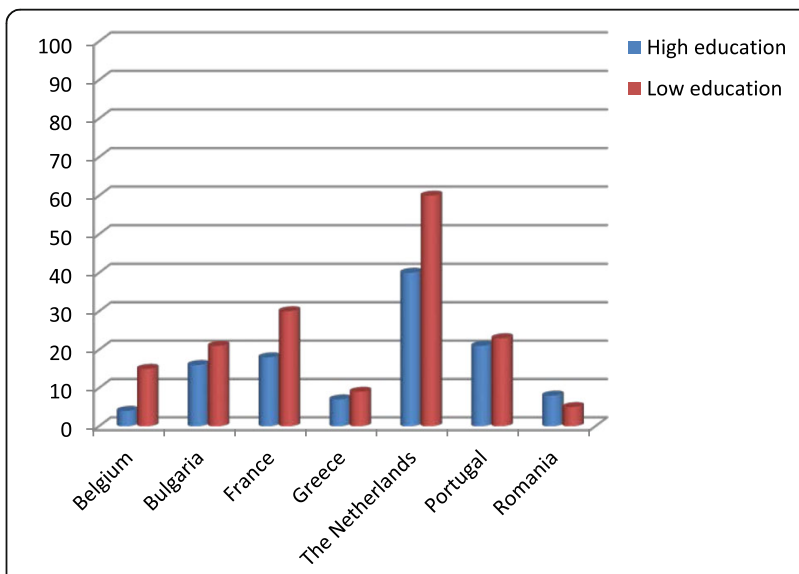

Fig. 2 Percentage of population lost-to follow-up at $T_{1}$ per educational group per country 


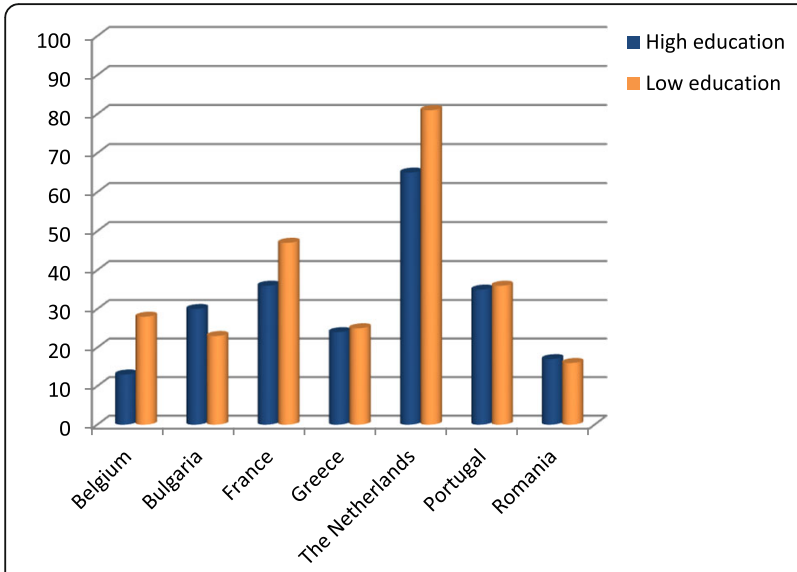

Fig. 3 Percentage of population lost-to follow-up at $T_{2}$ per educational group per country

presented in Additional files 1, 2, 3, 4 and 5. Given the large amount of data, we chose to discuss the statistically significant changes only. In addition, considering the second objective of the study- to assess the sustainability of the improvements that occurred between pre and post-intervention period, Table 8 and Additional file 6 illustrate the sustainability of such changes.

\section{Changes in energy balance-related behaviours and their sustainability}

Tables 4, 5, 6, 7 shows changes in dietary intake, beverage intake, screen exposure and sleep hours, respectively, between the pre- and post- intervention period. Some

Table 4 Within-group comparison of median values and quartiles $\left(q_{1}-q_{3}\right)$ between $T_{0}-T_{1}$ for weekly dietary intake per education group

\begin{tabular}{|c|c|c|}
\hline & $\mathrm{T}_{0}$ & $\mathrm{~T}_{1}$ \\
\hline Education level & High & High \\
\hline
\end{tabular}

Country

\begin{tabular}{|c|c|c|c|c|}
\hline \multicolumn{5}{|c|}{ Fruit consumption (frequency/week) ${ }^{a}$} \\
\hline Portugal & $7(6-7)$ & $6(5-7)$ & $7(6-7)$ & $6(5-7)$ \\
\hline Romania & $6(4-6)$ & $5(4-6)$ & $6(4-6)$ & $6(4-6)$ \\
\hline The Netherlands & $6(6-7)$ & $5(4-6)^{* *}$ & $6(6-7)$ & $6(5-7)^{* *}$ \\
\hline \multicolumn{5}{|c|}{ Salad/grated vegetables consumption (frequency/week) ${ }^{a}$} \\
\hline Portugal & $6(4-7)$ & $5(4-7)$ & $6(5-7)$ & $6(4-6)$ \\
\hline \multicolumn{5}{|c|}{ Cooked vegetables consumption (frequency/week) ${ }^{a}$} \\
\hline Portugal & $7(6-7)$ & $6(5-7)$ & $7(6-7)$ & $6(5-7)$ \\
\hline Romania & $5(4-6)$ & $4(3-6)$ & $5(4-6)$ & $4(4-6)$ \\
\hline
\end{tabular}

Comparison between the educational groups of each country and the total sample with Wilcoxon signed rank test. Rounded values are presented ${ }^{a}$ Response categories: 1 .Never 2.Less than one day per week 3.One day per week 4.2-4 days a week 5.5-6 days a week 6.Every day, once a day 7.Every day, twice a day 8 .Every day, more than twice a day

**significant within-group difference at .01 behaviours were improved among the low socioeconomic groups, reducing the inequality gaps between children from low and high socio-economic background that were identified at baseline. However, a few worsening trends were observed as well within both the low and the high educational groups at $\mathrm{T}_{1}$; besides that, few of the improved changes were sustained at $\mathrm{T}_{2}$.

More specifically, the frequency of fruit intake increased significantly within the Dutch low education group (Table 4), reaching the same frequency as in the high education group. A small, but statistically significant decrease in the consumption of fruit juices was seen within the Romanian low education group (Table 5). TV time during weekdays decreased among the Belgian children from the low educational group (Table 6). Moreover, computer time both during weekdays and during weekend days increased significantly within the Bulgarian high education group, resulting in higher screen exposure during the week (Table 6). Computer time during weekends also increased in the Romanian sample, however, within the low education group (Table 6). No notable changes were found with respect to sleep hours (Table 7).

A year after the interventions, two of the aforementioned changes were sustained, namely the increased fruit intake among the Dutch low education group and the decrease of TV time spent on weekdays among the Belgian low education status group (Table 8).

\section{Changes in determinants of energy balance-related behaviours and their sustainability}

Similarly to the behavioural changes, we found a few statistically significant changes related to inequality gaps identified at baseline in the determinants of the assessed behaviours, within the low and within the high education groups in all countries, and again few of the reduced gaps were sustained.

In particular, no noteworthy changes were observed related to the determinants of fruit and vegetable consumption (Additional file 1). Parental practices related to the consumption of fruit juices improved in families with a low educational status background in Belgium (parental allowance), Greece (negotiate parental allowance) and Portugal (rewarding/comforting practice; Additional file 2). The latter was sustained a year after the interventions (Additional file 6).

For the determinants of soft drinks consumption, the observed effects were mixed. As illustrated in Additional file 3, in France the children of highly educated mothers complained more often when soft drinks were not allowed (nagging), whereas Romanian parents from a low educational background increased the frequency of drinking soft drinks in the presence of their child (avoid negative modelling; Additional file 3) compared to baseline. In contrast, a noteworthy change in 
Table 5 Within-group comparison of median values and quartiles $\left(q_{1}-q_{3}\right) T_{0}-T_{1}$ for weekly beverage intake per education group

\begin{tabular}{|c|c|c|c|c|}
\hline \multirow[b]{2}{*}{ Education level } & \multicolumn{2}{|c|}{$\mathrm{T}_{0}$} & \multicolumn{2}{|c|}{$\mathrm{T}_{1}$} \\
\hline & High & Low & High & Low \\
\hline \multicolumn{5}{|l|}{ Country } \\
\hline \multicolumn{5}{|l|}{ Fruit juices frequency ${ }^{a}$} \\
\hline Romania & $4(3-6)$ & $4(2-4)$ & $4(3-4)$ & $3(3-4)$ \\
\hline \multicolumn{5}{|c|}{ Fruit juices amount $(\mathrm{ml})^{b}$} \\
\hline Belgium & $500(250-580)$ & $580(500-750)$ & $500(250-580)$ & $580(250-830)$ \\
\hline Bulgaria & $580(500-830)$ & $830(580-1160)$ & $580(540-830)$ & $580(250-830)$ \\
\hline Romania & $580(250-830)$ & $580(580-1060)^{* *}$ & $580(250-830)$ & $580(580-580)^{* *}$ \\
\hline The Netherlands & $250(250-500)$ & $250(250-580)$ & $500(250-580)$ & $500(250-580)$ \\
\hline \multicolumn{5}{|c|}{ Soft drinks frequency ${ }^{a}$} \\
\hline Portugal & $2(1-3)$ & $3(2-3)$ & $2(1-3)$ & $2(2-3)$ \\
\hline Romania & $2(1-3)$ & $3(2-4)$ & $2(1-3)$ & $3(2-4)$ \\
\hline \multicolumn{5}{|c|}{ Soft drinks amount $(\mathrm{ml})^{\mathrm{b}}$} \\
\hline Portugal & $250(125-580)$ & $580(250-580)$ & $250(250-580)$ & $580(250-580)$ \\
\hline Romania & $580(125-915)$ & $1000(500-1160)$ & $580(250-1080)$ & $580(250-1080)$ \\
\hline
\end{tabular}

Portugal was observed, namely the decreased home availability of soft drinks among the low education group (Additional file 3), which was maintained a year after the interventions (Additional file 6).

More changes were observed in the determinants of screen exposure. Parental practices and rules improved in some countries within families from a low educational background (i.e., increased monitoring of child's TV time (Belgium), increased efficacy to control TV exposure of the child (Greece), decreased allowance of TV watching (Portugal) (Additional file 4), except in the Netherlands (avoid less often computer use in the presence of the child) (Additional file 5). Among the high education group, parental negotiation for the allowed TV time increased in France, indicating less strict rules (Additional file 4). All of the aforementioned improvements within the low education group were being sustained a year after the interventions (Additional file 6).

\section{Results $\left(\mathrm{T}_{1}\right)$ after multiple testing adjustments}

Adjustments for multiple testing resulted in critical $p$-values lower than 0.05 (ranging from 0.000316 to 0.002532 ), as initially set by the authors (Additional file 7). Consequently, fewer of the differences found within the education groups of each of the samples (based on $\alpha=0.05$ ) were significant, based on the adjusted lower threshold (Additional file 7). As an illustration, the statistically significant differences within the Portuguese low education status group were initially 3 and after the adjustments this was reduced to 1 (Additional file 7). It was noteworthy that the decrease of TV time during weekdays among the Belgian low education group remained statistically significant (Additional file 7).

\section{Discussion}

After a one school-year (8/9-months) intervention period aiming at reducing inequality gaps between low and high socio-economic status children and their families in health behaviours and determinants, an improvement of three energy-balance related behaviours among the low socio-economic status groups was observed, namely an increase of fruit consumption (Netherlands), decrease in the amount fruit juices consumed (Romania) and decrease of TV time on weekdays (Belgium). Whereas in only the latter case was the behavioural change accompanied by an improvement in a familyenvironmental determinant (monitoring the time the child watches TV), other improvements in parental rules and practices related to soft drinks/fruit juices and TV exposure were observed. These results, however, cannot be exclusively attributed to the EPHE interventions, given that causality is not analysed in this study.

Our results are supported by two systematic reviews, which found positive changes in intervention studies 
Table 6 Within-group comparison of median values and quartiles $\left(q_{1}-q_{3}\right) T_{0}-T_{1}$ for screen exposure per education group

\begin{tabular}{|c|c|c|c|c|}
\hline \multirow[b]{2}{*}{$\begin{array}{l}\text { Education } \\
\text { level }\end{array}$} & \multicolumn{2}{|c|}{$\mathrm{T}_{0}$} & \multicolumn{2}{|c|}{$\mathrm{T}_{1}$} \\
\hline & High & Low & High & Low \\
\hline \multicolumn{5}{|l|}{ Country } \\
\hline \multicolumn{5}{|c|}{ TV weekdays (h/day) ${ }^{a}$} \\
\hline Belgium $^{d}$ & $3(2-4)$ & $5(3-6)^{* *}$ & $3(3-4)$ & $4(3-5)^{* *}$ \\
\hline France & $3(2-4)$ & $4(3-4)$ & $4(1-4)$ & $4(3-5)$ \\
\hline Greece & $3(2-4)$ & $4(3-4)$ & $3(2-4)$ & $3(3-4)$ \\
\hline Portugal $^{\mathrm{C}}$ & $3(2-4)$ & $3(3-4)$ & $3(3-4)$ & $3(3-4)$ \\
\hline Romania $^{c}$ & $3(3-4)$ & $4(3-6)$ & $3(3-5)$ & $4(3-6)$ \\
\hline \multicolumn{5}{|c|}{ TV weekend days (h/day) ${ }^{a}$} \\
\hline Belgium $^{d}$ & $5(4-7)$ & $7(5-8)$ & $5(4-7)$ & $6(4-7)$ \\
\hline France & $5(4-7)$ & $6(4-8)$ & $4(4-6)$ & $5(4-7)$ \\
\hline Portugal & $5(4-6)$ & $6(4-7)$ & $5(4-6)$ & $6(4-7)$ \\
\hline \multicolumn{5}{|c|}{ PC weekdays (h/day) ${ }^{a}$} \\
\hline Belgium $^{d}$ & $1(1-2)$ & $2(1-3)$ & $1(1-2)$ & $2(1-3)$ \\
\hline Bulgaria & $2(2-3)^{* *}$ & $3(2-3)$ & $3(2-3)^{* *}$ & $3(2-3)$ \\
\hline \multicolumn{5}{|c|}{ PC weekend days (h/day) ${ }^{a}$} \\
\hline Bulgaria & $3(2-4)^{*}$ & $4(3-5)$ & $4(3-5)^{*}$ & $4(3-4)$ \\
\hline Romania $^{c}$ & $4(2-5)$ & $3(1-5)^{* * *}$ & $4(3-6)$ & $5(3-6)^{* * *}$ \\
\hline \multicolumn{5}{|c|}{ Total screen time (h/week) ${ }^{b}$} \\
\hline Belgium $^{d}$ & $12.5(9-19)$ & $19.5(12-25)$ & $12(9-18)$ & $17(11-22.8)$ \\
\hline Bulgaria & $18(12-26)^{* *}$ & $23.50(13.5-30)$ & $20.5(13.5-29)^{* *}$ & $24(16-30)$ \\
\hline France & $14(9-24)$ & $17.5(11-22.5)$ & $10(16-22)$ & $18.3(11.4-23)$ \\
\hline Greece & $13.5(9.5-20.5)$ & $18(13-22.5)$ & $13.5(9.5-20)$ & $18.5(13.5-26)$ \\
\hline Portugal $^{c}$ & $14.5(10-20)$ & $17(11-23)$ & $15(12-22)$ & $17(12.5-22.5)$ \\
\hline
\end{tabular}

Comparison between the educational groups of each country and the total sample with Wilcoxon signed rank test. Rounded values are presented

${ }^{a}$ Response categories: 1. Not at all $2.30 \mathrm{~min} /$ day $3.1 \mathrm{~h} /$ day $4.2 \mathrm{~h} /$ day $5.2,5 \mathrm{~h} /$ day $6.3 \mathrm{~h} /$ day $7.3,5 \mathrm{~h} /$ day 8.4 or more h/day

${ }^{\mathrm{b}}$ The indicated amounts of hours are derived from the sum of the respective question items for TV (T1a and T1b) and PC time (T4a and T4b) [31]. The variables are categorical with specific values of hours in each category $c_{c}$ : the variables PC time for weekdays and weekend-days are measured with an extra response category for 1,5 h/day (coded as 4); as such the items include 9 response categories. This does not apply for the results of the total sample ${ }^{d}$ : the variables TV/PC time for weekdays and weekend-days are measured with an extra response category for $1,5 \mathrm{~h} /$ day (coded as 4); as such the items include 9 response categories. This does not apply for the results of the total sample

**, ***: significant within-group difference at .01 and .001 respectively

targeting behavioural changes, such as increase of physical activity and fruit and vegetable intake, decrease of screen time and intake of sugary beverages [19]. Most of these effective interventions were targeted at the low socio-economic status population, whereas only one was universal as the EPHE ones [19]. With regard to the changes we found in parental practices, observed primarily within the low socio-economic status groups, the improved values were similar or inclined towards the ones of the subjects of the respective high socio-economic status groups. These positive changes contradict the commonly
Table 7 Within-group comparison of median values and quartiles $\left(q_{1}-q_{3}\right) T_{0}-T_{1}$ for sleep hours per educational group

\begin{tabular}{|c|c|c|c|c|}
\hline \multirow[b]{2}{*}{ Education level } & \multicolumn{2}{|c|}{$\mathrm{T}_{0}$} & \multicolumn{2}{|c|}{$\mathrm{T}_{1}$} \\
\hline & High & Low & High & Low \\
\hline \multicolumn{5}{|l|}{ Country } \\
\hline \multicolumn{5}{|c|}{ Sleep duration weekdays (h/day) ${ }^{a}$} \\
\hline Portugal & $3(2-3)$ & $2(2-3)$ & $3(2-3)$ & $2(2-3)$ \\
\hline The Netherlands & $3(3-3)$ & $3(2-3)$ & $3(3-3)$ & $3(3-3)$ \\
\hline \multicolumn{5}{|c|}{ Sleep duration weekend days (h/day) ${ }^{a}$} \\
\hline The Netherlands & $3(3-3)$ & $3(2-3)$ & $3(3-3)$ & $3(3-3)$ \\
\hline
\end{tabular}

${ }^{a}$ Response categories: $1.6 \mathrm{~h}$ or less/per night $2.7 \mathrm{~h} /$ per night $3.8 \mathrm{~h} /$ per night $4.9 \mathrm{~h} /$ per night $5.10 \mathrm{~h} /$ per night 6. More than $10 \mathrm{~h}$ per night

observed phenomenon of the intervention-generated inequality $[9,11-15,17]$. Thus it seems that it is possible through universal interventions to reach, improve and even sustain the improvement of parental practices, including in low socio-economic status groups. This may even be related to sustained changes in behaviour, as indicated by the sustained decrease in TV time on weekdays (Belgium), which may in turn be associated with the sustained increase in monitoring the child's time spent watching television.

Nevertheless, a few statistically significant and usually small changes were observed in the assessed outcomes between the pre- and post-intervention period within the low socio-economic status groups and even fewer were sustained one year after. Consequently, some of the inequality gaps were decreased and sustained, but not all of them. One reason for this, apparently, was the short preparation time for designing the interventions, which impeded the programmes to implement those interventions targeted at inequality gaps in the determinants, as initially intended. Another reason was probably the short duration of the interventions and consequently their low intensity to be able to result in sustainable behaviour change. Two reviews concluded that intervention studies, of moderate to high quality, improved energybalance-related behaviours when implemented for more than six months, whereas community-based interventions delivered universally also reduced obesity-related outcomes of other kinds in all population groups in the long-term ( $>6$ months) $[9,19]$. Furthermore, a widening of inequalities was prevented through a multi-level, community capacity-building approach, in the medium to longer period ( $\geq 6$ months) $[9,19]$. It is worth mentioning the Fleurbaix-Laventie Ville Sante' study, based on the EPODE methodology, which showed a reduction in obesity prevalence in the lower socio-economic status group compared to the respective control group, only after conducting 12 years of community-based interventions [26]. Furthermore, Magneé et al. concluded from their assessement of universal interventions, that 
Table 8 Within-group comparison of median values and quartiles $\left(q_{1}-q_{3}\right)$ between $T_{1}-T_{2}$ for energy-balance related behaviours per education group

\begin{tabular}{|c|c|c|c|c|}
\hline \multirow[b]{2}{*}{ Education level } & \multicolumn{2}{|c|}{$\mathrm{T}_{1}$} & \multicolumn{2}{|c|}{$\mathrm{T}_{2}$} \\
\hline & High & Low & High & Low \\
\hline \multicolumn{5}{|l|}{ Country } \\
\hline \multicolumn{5}{|c|}{ Fruit consumption (frequency/week) ${ }^{a}$} \\
\hline The Netherlands & $7(6-7)$ & $6(5-7)$ & $7(6-7)$ & $6(4-6)$ \\
\hline \multicolumn{5}{|c|}{ Fruit juices amount $(\mathrm{ml})^{\mathrm{b}}$} \\
\hline Romania & $580(250-830)$ & $580(250-580)^{* * *}$ & $580(580-830)$ & $580(580-830)^{* *}$ \\
\hline \multicolumn{5}{|c|}{ TV time weekdays $\left(\mathrm{h} /\right.$ day) ${ }^{c}$} \\
\hline Belgium ${ }^{d}$ & $3(2-4)$ & $4(3-5)$ & $3(2-4)$ & $4(3-5)$ \\
\hline \multicolumn{5}{|c|}{ 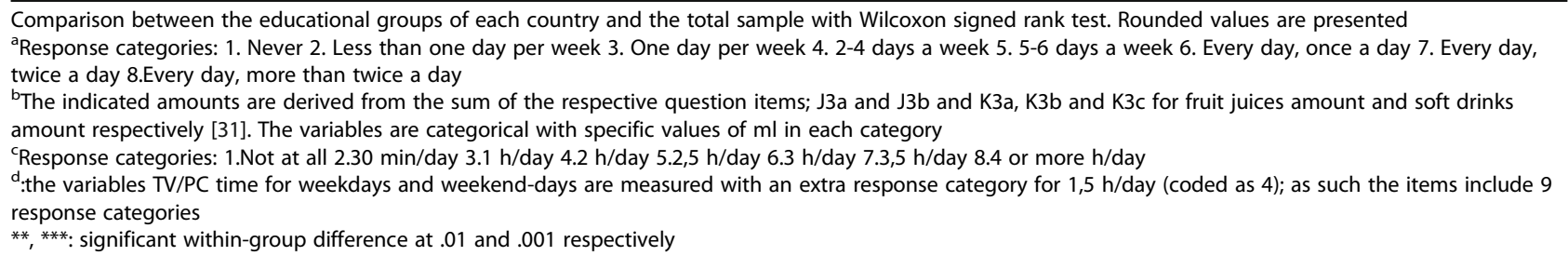 } \\
\hline
\end{tabular}

socio-economic inequalities in physical activity, diet or prevention of obesity are most likely to be reduced through intensive community level interventions, underlining the importance of tailoring interventions to the needs of low socio-economic status populations [13]. Whereas we considered the tailoring as selecting behaviours and determinants of behaviours that differed and therefore should be our target, the literature shows that tailoring should involve an investigation of the target population [45-47] and require participation of the target population in the development of interventions [48]. This was not possible in the EPHE project because of time constrains.

\section{Strengths and limitations}

To our knowledge, this is the first evaluation study that provides data on socio-economic inequalities in familyenvironmental determinants associated with energybalance related behaviours across a wide variety of European countries. Translation and back translation procedures in the development of the questionnaires enabled comparisons of the study results across countries. The cross-cultural character of the sample enables the exploration of inequalities in factors that have been strongly associated with childhood obesity. Such studies may be especially important in the light of the rapidly changing economic circumstances in many parts of the Europe. In addition, our results provide new insight into energy-balance behaviours and their determinants, which should be the focus for the development of effective interventions aimed at reducing inequalities in childhood obesity.
However, our study has certain limitations. For the purpose of the EPHE evaluation study, the participant programmes were selected on the basis of towns or locations that were already actively involved with EPODE. They may not be representative of the countries in which they are located and may have resulted in the selection of towns where already ongoing community-based interventions had resulted in changes in behaviour. In addition, the schools from which the samples were recruited were selected based on accessibility and convenience criteria. The results of this study must be therefore interpreted and generalized with caution. Moreover, the higher drop-out of subjects from the low education group may have impeded the power of this study to detect significant effects after the interventions and/or their potential sustainability.

In addition the population of the middle socioeconomic status group was divided among the population of high and low socio-economic status, due to the small number of subjects in the lowest educational category. Thus the ability to detect big differences among the cohorts might be limited. Another weakness of this study could be that we used the educational level of the mother as a proxy for socio-economic status, instead of using a wider set of indicators. Although the parental education level has been characterised as an adequate socio-economic indicator by relevant and more elaborative studies [40-42], this still reduces the strength of detecting absolute inequalities. It is important to mention that the power of the associations observed is decreased, due to loss-to-follow-up, especially in the Dutch sample, of which the size was considerably reduced. Furthermore this study reports selectively on the statistically 
significant changes, which were considerably reduced after adjustments for multiple testing. Yet, we consider our results important as they give indications that improvements in lifestyle behaviours among low socio-economic status groups are possible. Moreover it seems that small changes may contribute to tackling the public health problem of obesity on population level.

Moreover, the data were self-reported and recall bias and/or socially desirable answers are possible as in nearly all large scale community interventions. Besides, a disadvantage of using the same questionnaire across all countries was that not all items are as relevant for all countries. Furthermore, errors from the constructed items are possible, given that they were not validated. In addition, this is an effect evaluation, which did not use a control group. Thus, conclusions about causality cannot be drawn, the effects cannot be exclusively attributed to the interventions, and neither can conclusions on the quality of the interventions that were carried out be drawn.

\section{Implications for public health practice}

The results of our study seem to support the view that improvement in energy-balance related behaviours and parental rules and practices in the low socio-economic status populations is feasible by implementing interventions designed on the basis of studied gaps, and tailored to the behaviours and determinants that differed between low and high socio-economic status families, within an existing health promotion programme that is already targeting the whole population. However the short duration leads to only moderate favourable changes, besides the very low potential to sustain improvement.

\section{Implications for public health research}

Inequalities in family environmental determinants- such as parental rules and availability of fruit, vegetables, sugary-sweetened beverages and screens in the personal space of the child- may be addressed with more success by upstream, high intensity, long-term and multi-level interventions. Therefore further studies including the use of a control group are needed, to establish the ability of such interventions to reduce inequalities in obesityrelated determinants and behaviours. Further studies could assess whether existing social-marketing strategies could help or whether such strategies should be intensified when aiming at reducing socio-economic gaps.

\section{Conclusions}

The improvements in behaviours and determinants observed among children of both high and low socioeconomic status, indicate that inequalities in obesityrelated behaviours could be potentially reduced when implementing community-based interventions universally delivered, targeting those behaviours and determinants where inequalities exist, and being developed according to the EPODE methodology. The results showed large variability in the observed changes after the implemented interventions, while the monitoring of interventions and process evaluation is crucial to understand the observed results. Future research is necessary, evaluating more tailored interventions and upstream and environmental interventions that require targeted health policies.

\section{Additional files}

Additional file 1: Within-group changes $\left(T_{0}-T_{1}\right)$ in median values $\left(q_{1}-q_{3}\right)$ in the determinants of fruit and vegetable consumption. (DOCX $20 \mathrm{~kb}$ )

Additional file 2: Within-group changes $\left(T_{0}-T_{1}\right)$ in median values $\left(q_{1}-q_{3}\right)$ in the determinants of fruit juices consumption. (DOCX 18 kb)

Additional file 3: Within-group changes $\left(T_{0}-T_{1}\right)$ in median values $\left(q_{1}-q_{3}\right)$ in the determinants of soft drinks consumption. (DOCX 18 kb)

Additional file 4: Within-group changes $\left(T_{0}-T_{1}\right)$ in median values $\left(q_{1}-q_{3}\right)$ in the determinants of TV exposure. (DOCX $21 \mathrm{~kb}$ )

Additional file 5: Within-group changes $\left(T_{0}-T_{1}\right)$ in median values $\left(q_{1}-q_{3}\right)$ in the determinants of PC exposure. . (DOCX $18 \mathrm{~kb}$ )

Additional file 6: Within-group changes $\left(T_{1}-T_{2}\right)$ in median values $\left(q_{1}-q_{3}\right)$ in determinants per behavior. (DOCX $20 \mathrm{~kb}$ )

Additional file 7: Corrected critical $p$-values after adjustment for multiple testing $\left(\mathrm{T}_{1}\right)$. (DOCX $\left.34 \mathrm{~kb}\right)$

\section{Abbreviations}

EPODE: Ensemble Prévenons I'Obésité Des Enfants-Together let's prevent obesity; EPHE: EPODE for the promotion of health equity; PC: Personal computer

\section{Acknowledgements}

We acknowledge the significant contribution of the EPHE Operational Board to the data acquisition and all related processes. We would like to thank the involved school personnel of all countries for permitting and assisting the data collection. In addition, we would like to thank all parents/caretakers for their participation to the study.

\section{Funding}

This research is funded by the European Commission, DG SANCO. The EPHE Project is co-funded by the DG SanCO.

\section{Availability of data and material}

The datasets during and/or analysed during the current study available from the corresponding author on reasonable request.

\section{Authors' contributions}

All authors participated to the design of the study. AV, MJG, PG, GR, SH, JMB, $\mathrm{HdP}, \mathrm{TLSV}$ and SH were responsible for monitoring the data collection process. KM and AV conducted the statistical analysis. KM prepared the initial draft of the manuscript. All authors contributed to the writing of the manuscript and critically revised the manuscript. JCS supervised the data analysis and writing of the manuscript. All authors approved the final version of the manuscript.

\section{Competing interests}

The Authors declare that they have no competing interests.

Consent for publication

Not applicable. 


\section{Ethics approval and consent to participate}

The survey obtained a permission waiver from the Medical Ethics Committee of the VU University Medical Centre.

\section{Author details}

'Department of Health Sciences, VU University Amsterdam, De Boelelaan 1085, 1081 HV Amsterdam, The Netherlands. ${ }^{2}$ Department of Agricultural Economics and Rural Development, Agricultural University of Athens, Athens,

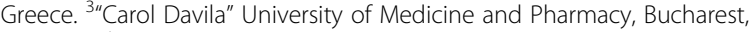
Romania. ${ }^{4}$ EPODE European Network Coordinating Team, Proteines, Paris, France. ${ }^{5}$ Faculty of Nutrition and Food Sciences, University of Porto, Porto, Portugal. ${ }^{6}$ Directorate General of Health, Lisbon, Portugal. ${ }^{7}$ Department of Public Health, Ghent University, Ghent, Belgium. ${ }^{8}$ Bulgarian Association for the study of Obesity and related diseases, Sofia, Bulgaria. ${ }^{9}$ Research Centre for the Prevention of Overweight, Windesheim University of Applied Sciences Zwolle, Zwolle, The Netherlands. ${ }^{10}$ Research Centre for the Prevention of Overweight, VU University, Zwolle, The Netherlands.

\section{Received: 10 February 2016 Accepted: 7 September 2016}

\section{Published online: 29 September 2016}

\section{References}

1. Devaux M, Sassi F. Social inequalities in obesity and overweight in 11 OECD countries. Eur J Public Health. 2013;23(3):464-9.

2. Di Cesare $M$, Khang $Y H$, Asaria P, Blakely T, Cowan MJ, Farzadfar F, Guerrero R, Ikeda N, Kyobutungi C, Msyamboza KP, Oum S, Lynch JW, Marmot MG, Ezzati M. Inequalities in non-communicable diseases and effective responses. Lancet (London, England). 2013;381(9866):585-97.

3. Robertson A, Lobstein T, Knai C. Obesity and socio-economic groups in Europe: Evidence review and implications for action. In: European Commission, report for DG Sanco. 2007. http://ec.europa.eu/health/ph_ determinants/life_style/nutrition/documents/ev20081028_rep_en.pdf. Accessed 11 Jan 2016.

4. Loring B, Robertson A. Obesity \& inequities. Guidance for addressing inequities in overweight and obesity. In: European Office for Investment for Health \& Development, Venice World Health Organization, Regional Office for Europe. 2014. http://www.euro.who.int/_data/assets/pdf_file/0003/ 247638/obesity-090514.pdf. Accessed 11 Jan 2016

5. WHO. WHO European Ministerial Conference on Nutrition and Noncommunicable Diseases in the Context of Health 2020. In: WHO Vienna. 2013. http://www.euro.who.int/_data/assets/pdf_file/0009/193878/ViennaDeclaration.pdf. Accessed 11 Jan 2016

6. White MAJ, Heywood P. How and why do interventions that increase heath overall widen inequalities within populations? In: BS J, editor. Social Inequality and Public Health. Bristol: Policy Press; 2009. p. 65-81.

7. Marmot M, Allen J, Bell R, Bloomer E, Goldblatt P. WHO European review of social determinants of health and the health divide. Lancet (London, England). 2012;380(9846):1011-29.

8. Pikhartova J, Blane D, Netuveli G. The role of childhood social position in adult type 2 diabetes: evidence from the English Longitudinal Study of Ageing. BMC Public Health. 2014;14:505

9. Hillier-Brown FC, Bambra CL, Cairns JM, Kasim A, Moore HJ, Summerbell CD. A systematic review of the effectiveness of individual, community and societal level interventions at reducing socioeconomic inequalities in obesity amongst children. BMC Public Health. 2014;14:834.

10. Bambra CL, Hillier FC, Moore HJ, Cairns-Nagi JM, Summerbell CD. Tackling inequalities in obesity: a protocol for a systematic review of the effectiveness of public health interventions at reducing socioeconomic inequalities in obesity among adults. Syst Rev. 2013;2:27.

11. Grydeland M, Bergh $\mathbb{H}$, Bjelland M, Lien N, Andersen LF, Ommundsen $Y$, Klepp KI, Anderssen SA. Intervention effects on physical activity: the HEIA study - a cluster randomized controlled trial. Int J Behav Nutr Phys Act. 2013;10:17.

12. Lorenc $T$, Petticrew M, Welch $V$, Tugwell $P$. What types of interventions generate inequalities? Evidence from systematic reviews. J Epidemiol Community Health. 2013;67(2):190-3.

13. Magnee T, Burdorf A, Brug J, Kremers SP, Oenema A, van Assema P, Ezendam NP, van Genugten L, Hendriksen IJ, Hopman-Rock M, Jansen W, de Jong J, Kocken PL, Kroeze W, Kwak L, Lechner L, de Nooijer J, van Poppel MN, Robroek SJ, Schreurs H, van Sluijs EM, Steenhuis IJ, van Stralen MM, Tak NI, te Velde SJ, Vermeer WM, Wammes B, van Wier MF, van Lenthe FJ. Equity-specific effects of 26 Dutch obesity-related lifestyle interventions. Am J Prev Med. 2013;44(6):e57-66.

14. McGill R, Anwar E, Orton L, Bromley H, Lloyd-Williams F, O'Flaherty M, Taylor-Robinson D, Guzman-Castillo M, Gillespie D, Moreira P, Allen K, Hyseni L, Calder N, Petticrew M, White M, Whitehead M, Capewell S. Are interventions to promote healthy eating equally effective for all? Systematic review of socioeconomic inequalities in impact. BMC Public Health. 2015;15:457.

15. Vander Ploeg KA, Maximova K, McGavock J, Davis W, Veugelers P. Do school-based physical activity interventions increase or reduce inequalities in health? Soc Sci Med (1982). 2014;112:80-7.

16. Hart JT. The inverse care law. Lancet (London, England). 1971;1(7696): 405-12.

17. Hillier-Brown FC, Bambra CL, Cairns-Nagi JM, Kasim A, Moore HJ, Summerbell CD. A systematic review of the effectiveness of individual, community and societal level interventions at reducing socioeconomic inequalities in obesity amongst adults. Int J Obes (Lond). 2014;38(12): 1483-90.

18. Victora CG, Vaughan JP, Barros FC, Silva AC, Tomasi E. Explaining trends in inequities: evidence from Brazilian child health studies. Lancet (London, England). 2000;356(9235):1093-8.

19. Bambra CL, Hillier FC, Cairns JM, Kasim A, Moore HJ, Summerbell CD. Public Health Research. In: How effective are interventions at reducing socioeconomic inequalities in obesity among children and adults? Two systematic reviews. Southampton (UK); 2015.

20. Moore GF, Littlecott HJ, Turley R, Waters E, Murphy S. Socioeconomic gradients in the effects of universal school-based health behaviour interventions: a systematic review of intervention studies. BMC Public Health. 2015;15(1):907.

21. De Craemer M, De Decker E, Verloigne M, De Bourdeaudhuij I, Manios Y, Cardon G. The effect of a kindergarten-based, family-involved intervention on objectively measured physical activity in Belgian preschool boys and girls of high and low SES: the ToyBox-study. Int J Behav Nutr Phys Act. 2014;11(1):38

22. Laws R, Campbell KJ, van der Pligt P, Russell G, Ball K, Lynch J, Crawford D, Taylor R, Askew D, Denney-Wilson E. The impact of interventions to prevent obesity or improve obesity related behaviours in children (0-5 years) from socioeconomically disadvantaged and/or indigenous families: a systematic review. BMC Public Health. 2014;14:779.

23. Tugwell P, de Savigny D, Hawker G, Robinson V. Applying clinical epidemiological methods to health equity: the equity effectiveness loop. BMJ (Clinical Research Ed). 2006;332(7537):358-61.

24. Borys JM, Le Bodo Y, Jebb SA, Seidell JC, Summerbell C, Richard D, De Henauw S, Moreno LA, Romon M, Visscher TL, Raffin S, Swinborn B, the EEN study group. EPODE approach for childhood obesity prevention: methods, progress and international development. Obes Rev. 2012;13(4): 299-315.

25. Van Koperen TM, Jebb SA, Summerbell CD, Visscher TL, Romon M, Borys JM Seidell JC. Characterizing the EPODE logic model: unravelling the past and informing the future. Obes Rev. 2013;14(2):162-70.

26. Romon M, Lommez A, Tafflet M, Basdevant A, Oppert JM, Bresson JL, Ducimetiere P, Charles MA, Borys JM. Downward trends in the prevalence of childhood overweight in the setting of 12-year school- and communitybased programmes. Public Health Nutr. 2009;12(10):1735-42.

27. de Jong E, Stocks T, Visscher TL, HiraSing RA, Seidell JC, Renders CM. Association between sleep duration and overweight: the importance of parenting. Int J Obes (Lond). 2012;36(10):1278-84.

28. Olafsdottir S, Berg C, Eiben G, Lanfer A, Reisch L, Ahrens W, Kourides Y, Molnar D, Moreno LA, Siani A, Veidebaum T, Lisner L. Young children's screen activities, sweet drink consumption and anthropometry: results from a prospective European study. Eur J Clin Nutr. 2014;68(2):223-8.

29. Roblin L. Childhood obesity: food, nutrient, and eating-habit trends and influences. Appl Physiol Nutr Metab. 2007;32(4):635-45.

30. Santaliestra-Pasias AM, Rey-Lopez JP, Moreno Aznar LA. Obesity and sedentarism in children and adolescents: what should be bone? Nutr Hosp. 2013;28 Suppl 5:99-104.

31. Mantziki K, Vassilopoulos A, Radulian G, Borys JM, Du Plessis H, Gregorio MJ, Graca P, De Henauw S, Handjiev S, Visscher TL, Seidell JC. Inequities in energy-balance related behaviours and family environmental determinants in European children: baseline results of the prospective EPHE evaluation study. BMC Public Health. 2015;15(1):1203. 
32. Mantziki K, Vassilopoulos A, Radulian G, Borys JM, du Plessis H, Gregorio MJ, Graca P, de Henauw S, Handjiev S, Visscher TL, Seidell JC. Promoting health equity in European children: design and methodology of the prospective EPHE (Epode for the Promotion of Health Equity) evaluation study. BMC Public Health. 2014;14(1):303.

33. Borys JM, Graca P, Gregorio MJ, Handjiev S, Mantziki K, Moreno AL, Du Plessis H, Seidell JC, Vassilopoulos A, Visscher TL. EPODE for the Promotion of Health Equity. France: Lavoisier; 2015.

34. van Stralen MM, te Velde SJ, Singh AS, De Bourdeaudhuij I, Martens MK, van der Sluis M, Manios Y, Grammatikaki E, Chinapaw MJ, Maes L, Bere E, Jensen J, Moreno L, Jan N, Molnar D, Moore H, Brug J. EuropeaN Energy balance Research to prevent excessive weight Gain among Youth (ENERGY) project: Design and methodology of the ENERGY cross-sectional survey. BMC Public Health. 2011;11:65.

35. De Bourdeaudhuij I, Klepp Kl, Due P, Rodrigo CP, de Almeida M, Wind M, Krolner R, Sandvik C, Brug J. Reliability and validity of a questionnaire to measure personal, social and environmental correlates of fruit and vegetable intake in 10-11-year-old children in five European countries. Public Health Nutr. 2005;8(2):189-200.

36. Fischer C, Brug J, Tak NI, Yngve A, te Velde SJ. Differences in fruit and vegetable intake and their determinants among 11-year-old schoolchildren between 2003 and 2009. Int J Behav Nutr Phys Act. 2011;8:141.

37. Tolonen H: EHES Manual. Part B. Fieldwork procedures. In. Helsinki: National Institute for Health and Welfare. 2013. https://www.julkari.fi/bitstream/ handle/10024/104392/URN_ISBN_978-952-245-843-8.pdf?sequence=1. Accessed 11 Jan 2016

38. European Social Survey. ESS Round 6 Source Questionnaire. In: London: Centre for Comparative Social Surveys. London: European Social Survey; 2012.

39. United States DoA, Economic Research Service. In: U.S. Household Food Security Survey Module: Six-Item Short Form Economic Research Service, USDA. http://www.ers.usda.gov/datafiles/Food_Security_in_the_United_ States/Food_Security_Survey_Modules/short2012.pdf. Accessed 11 Jan 2016

40. Bammann KGW, Lanfer A, Barba G, De Henauw S, Eiben G, Fernandez-Alvira JM, Kovács E, Lissner L, Moreno LA, Tornaritis M, Veidebaum T, Pigeot I, IDEFICS Consortium. Socioeconomic factors and childhood overweight in Europe: results from the multi-centre IDEFICS study. Pediatr Obes. 2013;8(1):1-12.

41. Fernandez-Alvira JM, Bammann K, Pala V, Krogh V, Barba G, Eiben G, Hebestreit A, Veidebaum T, Reisch L, Tornaritis M, Kovacs E, Huybrechts I, Moreno LA. Country-specific dietary patterns and associations with socioeconomic status in European children: the IDEFICS study. Eur J Clin Nutr. 2014;68(7):811-21.

42. Groth MV, Fagt S, Brondsted L. Social determinants of dietary habits in Denmark. Eur J Clin Nutr. 2001;55(11):959-66.

43. Hart A. Mann-Whitney test is not just a test of medians: differences in spread can be important. BMJ (Clinical research ed). 2001;323(7309):391-3.

44. Benjamini $Y$, Hochberg $Y$. Controlling the false discovery rate: a practical and powerful approach to multiple testing. J R Stat Soc. 1995;57(1):239-300

45. National Institute for Health and Care Exellence: Behaviour change: general approaches. https://www.nice.org.uk/guidance/ph6/chapter/introduction. (2007). Accessed 11 Jan 2016

46. Bartholomew-Eldredge L, Kay PGS, Kok G, Gottlieb Nell H, Fernández Maria E. Planning Health Promotion Programs: An Intervention Mapping Approach. 3rd ed. San Francisco: Jossey-Bass; 2011.

47. French J, Blair-Stevens C, McVey D, Merrit R. Social marketing and public health: Theory and practice. New York: Oxford University Press; 2010

48. Cargo M, Mercer SL. The value and challenges of participatory research: strengthening its practice. Annu Rev Public Health. 2008;29:325-50.

\section{Submit your next manuscript to BioMed Central and we will help you at every step:}

- We accept pre-submission inquiries

- Our selector tool helps you to find the most relevant journal

- We provide round the clock customer support

- Convenient online submission

- Thorough peer review

- Inclusion in PubMed and all major indexing services

- Maximum visibility for your research

Submit your manuscript at www.biomedcentral.com/submit
Biomed Central 